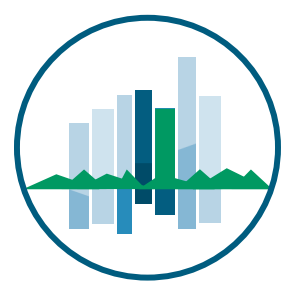

True Smart and Green City?

8th Conference of the

International Forum on Urbanism
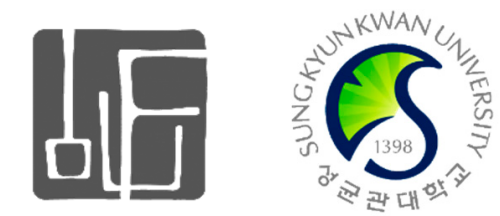

Conference Proceedings Paper

\title{
The Publicness Debate and Boundary Dialectics of Toad Hill Informal Settlement in Taipei, Taiwan
}

\author{
Yu-Wen Lin \\ Graduate Institute of Building and Planning, National Taiwan University, Taipei; \\ E-mail: linyuwendy@gmail.com
}

\begin{abstract}
Increasing anti-eviction social movements in Taipei are raising the question of the right to housing and the right to the city, Toad Hill settlement conservation movement is one of the focuses. Toad Hill settlement is an informal/squatter settlement that combines HuanMin military dependent village and informal settlement in the Taipei basin. Along the hillshaped landform, it remains pre-modern lifestyle, architecture form, and history layers, which could also regard as a historical settlement. The formation of Toad Hill settlement lies in the post-war urban development context, playing the role of social housing provision. This study aims to bring out the publicness debate in Toad Hill settlement. Another concern of the study is to identify the boundary dialectics when the settlement is on the way to transgress into urban life. The first part of the paper is framed with the discussion on the publicness debate in the historical settlement. From the political-economic perspective, the formation of Toad Hill settlement shows the relation between informal settlements and the institutionalized resources. Since the settlement released the housing crisis in the post-war Taipei, it represents a greater publicness. Also, through the production of the physical public spaces, it is clear that the residents redefine public space by a negotiating way. The bottom-up approach carried out by the residents shows an alternative mechanism of planning in a settlement scale. In addition, the intervention of the conservation movement brings the settlement, both the internal social structure and the relation between the settlement and the city, into the process of reterritorializing. For this reason, the second part of the paper focuses on identity and sense of place to examine the boundary dialectics of the settlement. With the method of participatory observation and qualitative research, the researcher has engaged in Toad Hill settlement conservation movement for two years starting from June 2013. The tendency shows that the boundary dialectics of an informal urban settlement may develop alternative renewal routes for a historical area. And the conservation movement, especially the process of proposing the citizen version planning vision, lay the foundation for a socially sustainable city.
\end{abstract}


Keywords: informal settlement, conservation, publicness, negotiated public, boundary

\section{Introduction}

Toad Hill settlement is an informal/squatter settlement that combines Huan-Min military dependent village, Japanese agriculture institute dormitories and informal households in the margin of Taipei basin. Along the hill-shaped landform, it remains pre-modern lifestyle, architecture form, and history layers, which is regarded as a historical settlement (as Figure 1). However, locating on the public-owned land, in the fringe of Taipei, Toad Hill settlement faces the informal settlement eviction. According to the land management authority, the settlement can separated into two parts by Alley 66, Lane 119, Section 4, Roosevelt Road. The west part land is managed by "National Taiwan University of Science and Technology" while the east part is managed by "National Property Administration" (as Table 1 and Figure 2). Therefore, the conservation movement raises in response to fighting the state control, bringing the settlement into the realm of urban planning and heritage conservation, in which both lay the public and legitimacy issue.

Figure 1. The overall view of the settlement.

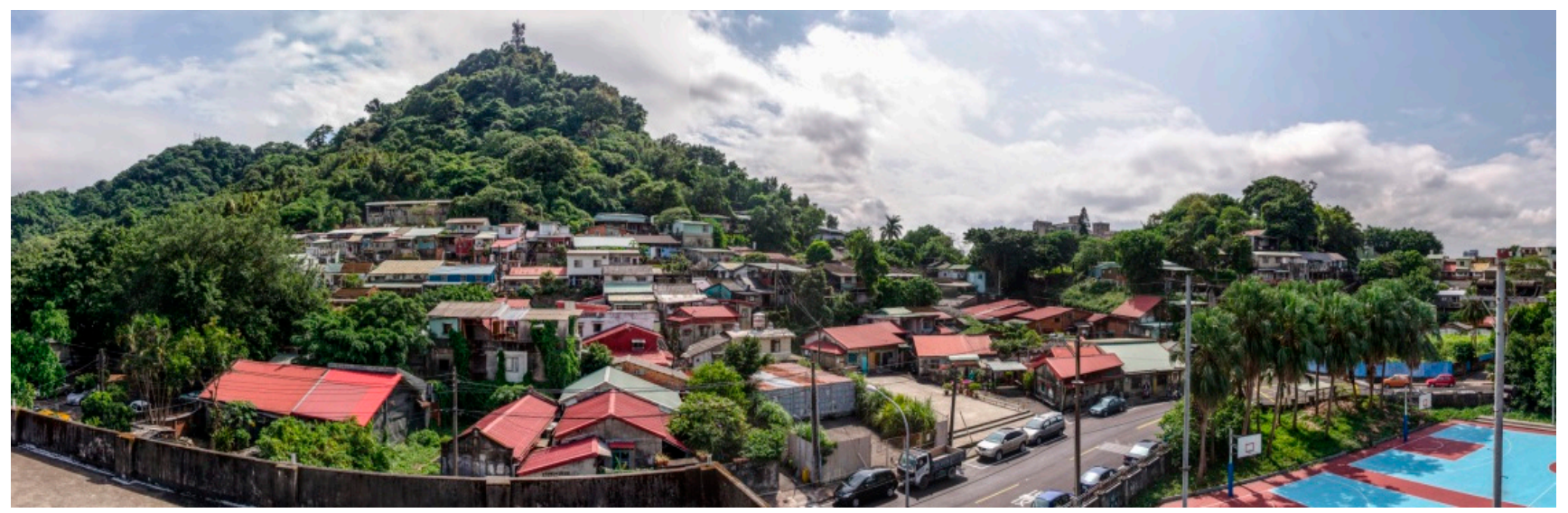

The research questions why Toad Hill settlement is regarded as an informal existence and how does the public meaning embody in the physical spaces in the settlement. From an individual household to a porch-corridor, to a cluster building group, to the bigger public spaces, and finally to the overall settlement, the accumulative spaces of different scales make up Toad Hill settlement. Behind the progressive spatial growth of the settlement is the negotiation of the households. Good living spaces formed through the demand-oriented design and construction. For the current urban planners, the spatial patterns and mechanism are also worth learning. Therefore, the research wonders how the historical background and social relations in the settlement formed such flexible public space. In the pre-modern settlement, the social relation forms and changes with various influences, from the existing social structure, the different clusters, to the new joint network brought in by the conservation group. Through the boundary debate, the research aims to uncover the dynamic social relations inside the settlement. 
Figure 2. The plan of the settlement.

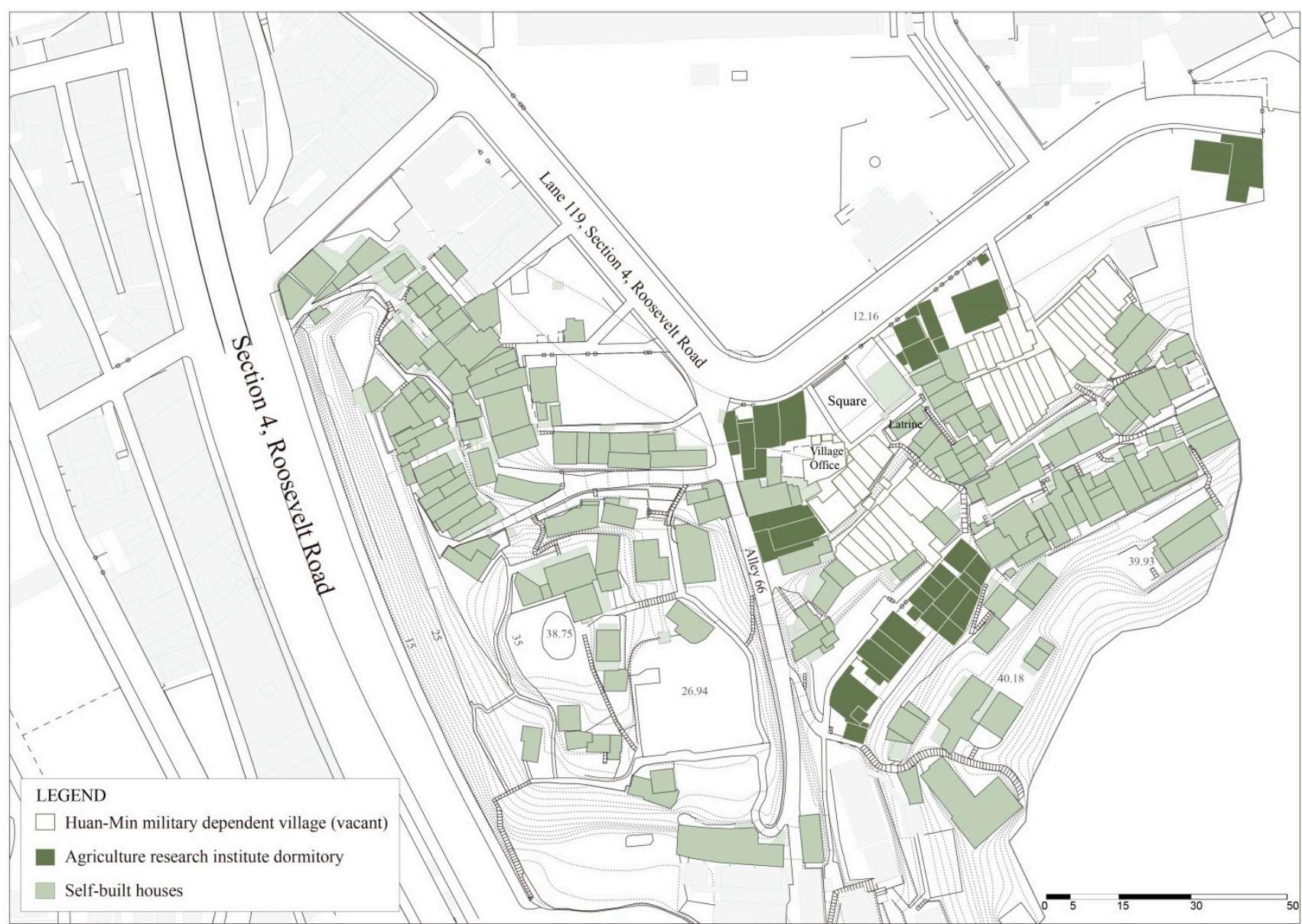

Table 1. The land use and household number.

\begin{tabular}{|l|l|l|}
\hline & West side & East side \\
\hline Land use zoning & Residential area & Academic area \\
\hline $\begin{array}{l}\text { land management } \\
\text { authority }\end{array}$ & $\begin{array}{l}\text { National Property } \\
\text { Administration, Ministry of } \\
\text { Finance }\end{array}$ & $\begin{array}{l}\text { National Taiwan University } \\
\text { of Science and Technology }\end{array}$ \\
\hline households & 64 & 92 \\
\hline
\end{tabular}

\section{Literature review}

The notion "public" and "private" is relatively defined by each other. A space is public or private contains variant meanings, it may refer to the land ownership, or refer to the right to access, especially whether it is restricted to some specific people or open to the general public, also, refer to the public or private character the activities taking place belong to. The public or private quality of the ownership, accessibility, and the activity often intertwine with different situations (王志弘等, 2009). According to Habermas, the idea of "public sphere" is that of a body of "private person" assembled to discuss matters of "public concern" or "common interest." At first this meant that state activities would be subject to 
critical scrutiny and the force of "public opinion." Later, it meant transmitting the considered "general interest" of "bourgeois society" to the state via forms of legally guaranteed free speech, free assembly, and eventually through the parliamentary institutions of representative government. (Fraser, 1992)

However, the conceptual models of the public sphere have moved toward multiplicity. Besides Habermas, feminist and African American scholars have taken the stance that there are multiple public spheres. Among them, Fraser provided a more complex picture of the marginal public sphere, called "counterpublics". Fraser (1992) defined "counterpublics" as, "Members of subordinated social groups-women, workers, peoples of color, and gays and lesbians-have repeatedly found it advantageous to constitute alternative publics. I propose to call these subaltern counterpublics in order to signal that they are parallel discursive arenas where members of subordinated social groups invent and circulate counterdiscourses, which in turn permit them to formulate oppositional interpretations of their identities, interests, and needs." Through social movements, the concept "counterpublics" transfers from the resistance of the subaltern groups into practice. The classic example raised by Fraser was the 20-century American feminism movement. On the other hand, Squires (2002) uses it to analyze the public spheres of the African Americans. She also reminds that subgroups within a counterpublic may have its internal heterogeneity. It is not necessarily for them to share same counter ideologies, participate in the production of counterdiscourses.

Back to what "public" is, Sennett (1988) pointed out that "Public" meant to the Greeks synoikismos, which is also the word for "making a city." From the definition of public, and the current issue that public space faces, it is obvious that publicness and the urbanism are inseparable. Therefore, when explore the meaning of public itself and public spaces, we could not leave the urban life behind. 夏鑄九(1994) pointed out that the distinguish between public and private explains the relation between the state and society. On this changing boundary, the political process of defining the boundary is the key point to raise questions. The debate between public and private carries out in the different level, even involves political contests in different scale. In Toad Hill settlement, there are two aspects of the public debate. The first one is the public-private status contention, which also known as the informal/ formal debate. The other happens to the physical spaces in the settlement. In those spaces, the production and the usage reflect the social relation of the households, including how they decided the width of the roads, how to solve the problems when the additional constructions affect other households' environmental quality.

Furthermore, the research regards Toad Hill settlement as an "urban settlement", a settlement that locates in the urban area. While, it specialty lies in the contradiction among urban and settlement. A settlement is the organism of human collective life. It could also mean a village that defined by a particular life scale, pattern, or territory (胡脤州 1977). While, from the scope of culture landscape, settlement may indicate some kind of pre-modernized rustic lifestyle. In addition, settlement is a meaningful collective living unit, which relates to the developing of local culture and identity building (享肇立 1998). As for urban, the reason why urban is unique is because of the aggregation of differences (Pile, 1999). It is possible to open up a new form of social relation, interaction, and opportunities. In other words, urban is an open intensive status. With mobility, fluidity and hybridity, urban is the place that with openness and interactive connectivity. Through trade, politics, and immigration, the city would able to become a place where culture mix and multiple narratives gather (Massey, 1995). 
In the discussion of places like urban settlement, especially the contradictions and differences among the two, the "sense of place" and "identity" are always the critical issue. Massey (1993) proposed the power geometry and the progressive sense of place. The place is not an actual space with actual boundary, but a process. What gives a place its identity and the specific characteristic is not only the local history but also the social relations that met and interact in some specific place. Also, it is important to know that a place boundary would not always be changing because the traditional of "place" was to discuss the boundary and territory. As Wills (2013) contended that only when "fixed to place" can people generate the sense of place and the identity, because people always live in place, in which people live daily and link to outside. Therefore, with the concept of "identity" and "sense of place", it could be possible to investigate the social boundaries within the settlement.

\section{The publicness debate}

The first public debate of Toad Hill settlement is its public or private status. From the domain viewpoint of land ownership, the settlement has been located on "public land" for hundred years. Some regard the formation of Toad Hill settlement as illegal households "occupying" and "privatizing" the public land, which is not only condemned as a shameful blemish of modernization but also have to endure the lawsuit and a great amount of fine.

I contend that it should take the political-economic perspective to comprehend the current informality status of Toad Hill settlement. The existence of the current informal settlement reflects the structural problems cause by the transfer of sovereignty. During the Japanese colonial time, the land belonged to the agriculture institute of the government. At the time, the institute was the pioneer of agriculture modernization. Some employees, who still live in the settlement, served as the agriculture diplomacy agents. Mr. Lin, for instance, went to Costa Rica to impart agriculture knowledge. After the Republic of China government came to Taiwan, the Air Force took over the land, not only in charge of the land surface but also part of the inner mountain, for building the secret cavern base. Followed the location of the Air Force, Huan-Min military dependent village was built in 1953, so as the other military dependent villages were built in elsewhere, but the limited amount housing projects could only provide to the privileged.

Therefore, the other two million political-forced refugees and the rural-urban migrants triggered off the housing issue in the post-war Taipei. Around 1950s, Taipei turned into the temporary military headquarters for counterattack. Most of the government resources and related planning were concentrated on military use, leaving the other parts of the city unplanned. Those who did not assign to houses squatted in public and private land, waterfront, and streets, therefore, formed the informal settlements (許訷榮, 1987). During the urbanization of Taipei city in 1960 to 1970s, lots of rural-urban migrants to the city for the better job opportunities. According to the Census in 1963, one-third of the households in Taipei lived in the informal settlement, in other words, the informal settlements become the "general landscape of Taipei” (史宓; 2000).

In short, the first layer of Toad Hill settlement was composed of the Japanese dormitories and the military dependent village which was greatly related to the institutionalized resources, as the 1958 figure shows. Then the second layer rapidly formed in the following 10 years since most of the veterans settled down and made up their families, as 1969 figure. Then in the 1980 figure, it shows the obvious trend of 
adding informal construction to increase home spaces. In this period, the rural-urban migrants and the urban poor had already moved in the settlement, whether rent houses or bought houses, after the first generation families left. In the marginal place, both as a metaphor and as the description of the location, the authentic hillside settlement comes into being, also holds the meaning of a social housing provision.

The formation of Toad Hill settlement shows the relation between informal settlements and the institutionalized resources. Since the so-called informal layer of the settlement "released the housing crisis" in the post-war Taipei, it represents a greater publicness. In conclusion, so as Fraser applied the concept counterpublic to challenge the domain public and what public is, the research uses counterpublic as a metaphor to draw an analogy between the existence of informal settlement and the formal planning space.

Figure 3. The evolution of settlement households.

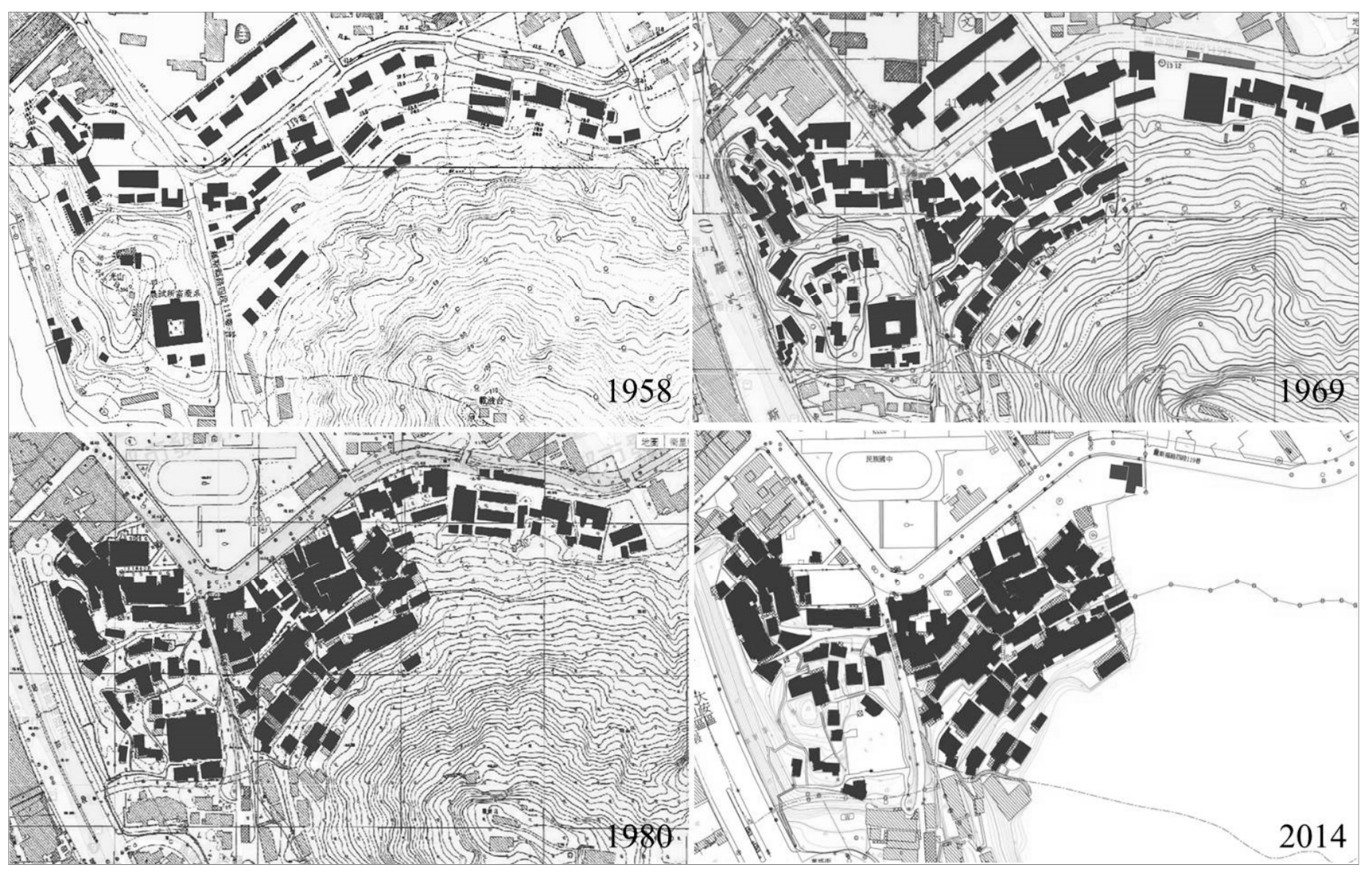

Another public debate goes to the physical space in Toad Hill settlement. In the self-built settlement, the negotiation and environmental control become the most relevant issue. Through the collective construct process, the residents define the land division in the settlement by the negotiating process. In the limited spaces, the private, semi-public, and the public space all closely connected together, sometimes transgress by different situations. Take Mr. Chen's as an example. There is a small platform in between his house and other five houses. Due to their close relation, in the process of extending housing space, they had the agreement to yield the small space for the public use. In the small space, sometimes they sit and chat, or play mahjong, while during the traditional festival, they worship gods or their ancestors in the place. Likewise, Mr. Chen and his neighbors constructed the stairs together by the stone to link to the platform. Through the collaborative constructing process, they not only build the 
physical space but also strengthen the identity of the home. It was not until few years before that the stone-made pavement was changed into cement by the aid of the chief of the village.

Aside from the small scale semi-public space, the porch-corridor space is another general pattern language which pertains to the negotiated public spaces in the settlement. The houses built along the contour, layer by layer, due to the hill-shaped terrain. The horizontal and vertical paths wove the public spaces like the fish bone. The porch-corridor spaces are the extend spaces of living area in the horizontal path. The common activities taking place in the porch-corridors are growing plants, hanging out clothes, chatting, and simply sitting. For instance, the Wang family is the first family to own a television, so after school, children would gather around in the porch-corridor outside Wang family, making there a popular social space. Similar activities occur often. Therefore, the residents have more opportunities to create close social relation in the porch-corridors of settlement.

Also, the public-private contention within the households is worth exploring, especially when the households were adding informal construction like the second floor, kitchen, and rooms. These different constructions, land grading, garden making in different times, regenerate their private space, however, it may affect the living qualities of the around neighbors, for instance, the right to sunshine and the width of the roads. In addition to the floor height, in the limited spaces, the houses connecting with each other, some are side by side, and some locate up and below. Mr. Pan's house locates on the hill ridge and Mr. Ting's house situates on the lower contour just below Mr. Pan's. When the Pan family decided to extend their space, they met the structure difficulties that once they launched the construction, their house would be on the top of the Ting's. Since at the time their houses were both constructed in the wood structure, it was not possible for the original house to bear the additional weight from the above. Therefor Mr. Pan took the initiative to negotiate with the Ting's about the renewal plan. They made a compromise that Mr. Pan would also pay the money to help reconstruct Ting's house into cement. Finally, in order to solve the structural problems that they ended up renewing into a longhouse that overlapped together.

Apart from the negotiation between the households and the private investment, the environmental improvement in semi-public and public spaces also involves the public sector resources. Those public resources somehow defined the boundaries of public space, for example, the road pavement renovation and the water pipes reset determined the width of the roads. In addition, large-scale constructions like the stone rip rap were fund by the village office. Interestingly, with the public resources investment, the environmental and spatial quality in the informal settlement is also control in fairness by the publicness.

\section{The boundary debate of the settlement}

The boundary between the city and the settlement not only define by its rural-like landscape, but also draw by the urban authorities. Toad Hill settlement locates in the margin of Taipei basin as if excluded by the urban system. Since the official boundary of Taipei city expanded in 1968, Kung-kuan turned out to be the central commercial area and the transportation node of southern Taipei. Seated in the south side Kung-kuan, Toad Hill settlement is separate by the provincial highway no. 9, Roosevelt road, and Keelong road, which draw a spatial boundary between the settlement and the city. As for the land exploiture, because the settlement is closely connected to the military area and the environmental-protect zone, the settlement could not expand more. The marginal character in the hidden location protects the settlement from the modern development. In this place, the authorities do not work well as if turning a 
blind eye to the squatting. Therefore, the social capital and the grassroots progressively lead the settlement into a self-organized place.

On the other hand, there are also inner boundary debates within the settlement. Through analyzing the clusters of the different identity, the overlapping spaces, and the negotiated public spaces, it is possible to comprehend the spatial-social relation in the settlement (as Figure 4). There are several factors to define "cluster", also known as the sub-area. One decisive factor is the ethnic groups shaped by the structural forces. The other factor is the location of the households, which also pertains to the time they moved in the settlement. The clusters compose the basic unit in the settlement. And the characteristics of each cluster are related to the identity of the residents. Inevitably, there is tension between each cluster. The most obvious tension is among the Mainlander households and the others local residents since the Mainlanders felt like they hold the higher hierarchy. Besides the external tension, each cluster contains its inner variety, for example, there are rural-urban migrant families and tenants in a military family cluster; the indigenous people in different cluster the residents also form their own identity cluster.

What's more important is that there are overlapping spaces between each cluster. These overlapping spaces turn out to be the public spaces in the settlement, especially the stairs that possess the largest area in the settlement. The longer the time to live in the settlement, the boundaries between each cluster becomes much vaguer, for instance, nowadays the Taiwanese households and the Mainlander households have already eliminated the past grudges and formed the sense of place.

Despite the cluster units, there are some activities that across the geographical limit. Among all the other activities, the folk dance and body-building dancing groups play the role of the public platform in the settlement. Every Monday to Saturday evening, women of different background households gather together to dance in the square, the biggest public space in the settlement. The women not only dance but also discuss the daily affairs in the settlement. Moreover, because the village office is nearby, the chief the village always brings the first-hand information to the women. The women would use the time to raise their problems to the office as well. The dancing place, therefore, becomes the public sphere in the settlement. As Figure 5 shows, the public farming on the square also brings residents from different clusters merge together.

In short, the cluster boundaries are always in a dynamic infiltrating condition. The sense of place in the settlement is also a continually changing process, which is constantly being re-understanding of contemporary social relation. Furthermore, the overlapping parts open the possibilities for the greater public. When looking back on the current urban planning system, the urban planning committee composed of experts and officials decide the land use and regulations of each piece of land in a topdown way, it is clear that it plays an objective role. However, the process excludes the subaltern publics. Outside the formal planning system, Toad Hill settlement demonstrates an alternative mechanism of spatial forming. Under the negotiation of the residents, the roads, streets, and alleys, become the spatial elements to integrate different clusters and the places where social activities happen. The negotiating land division represents a more public process of the settlement scale planning. Then from a single household, a cluster, to a bigger cluster, the settlement forms the collective identity. 
Figure 4. Social relation clusters.

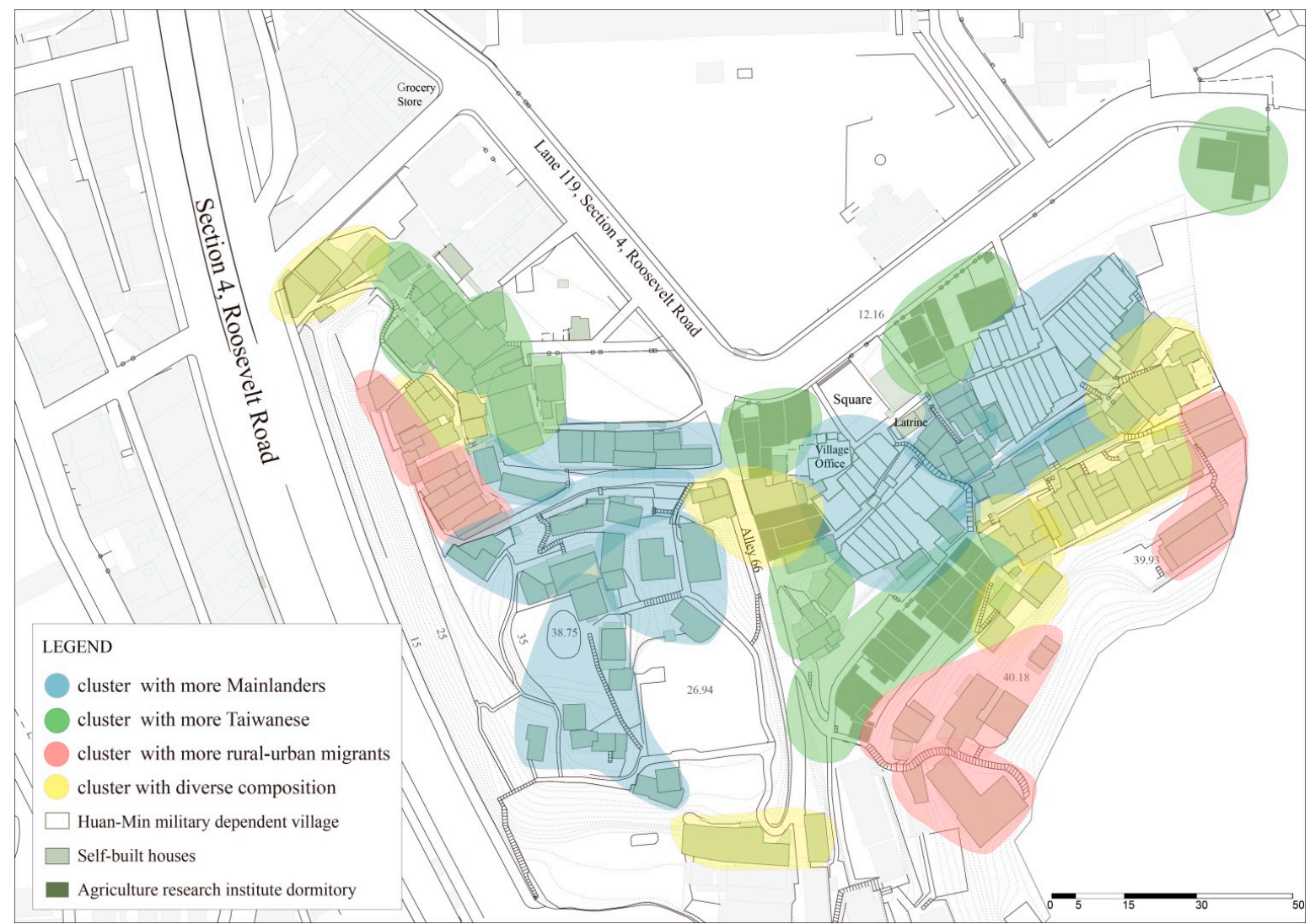

Figure 5. The infiltrating social relation in the settlement.

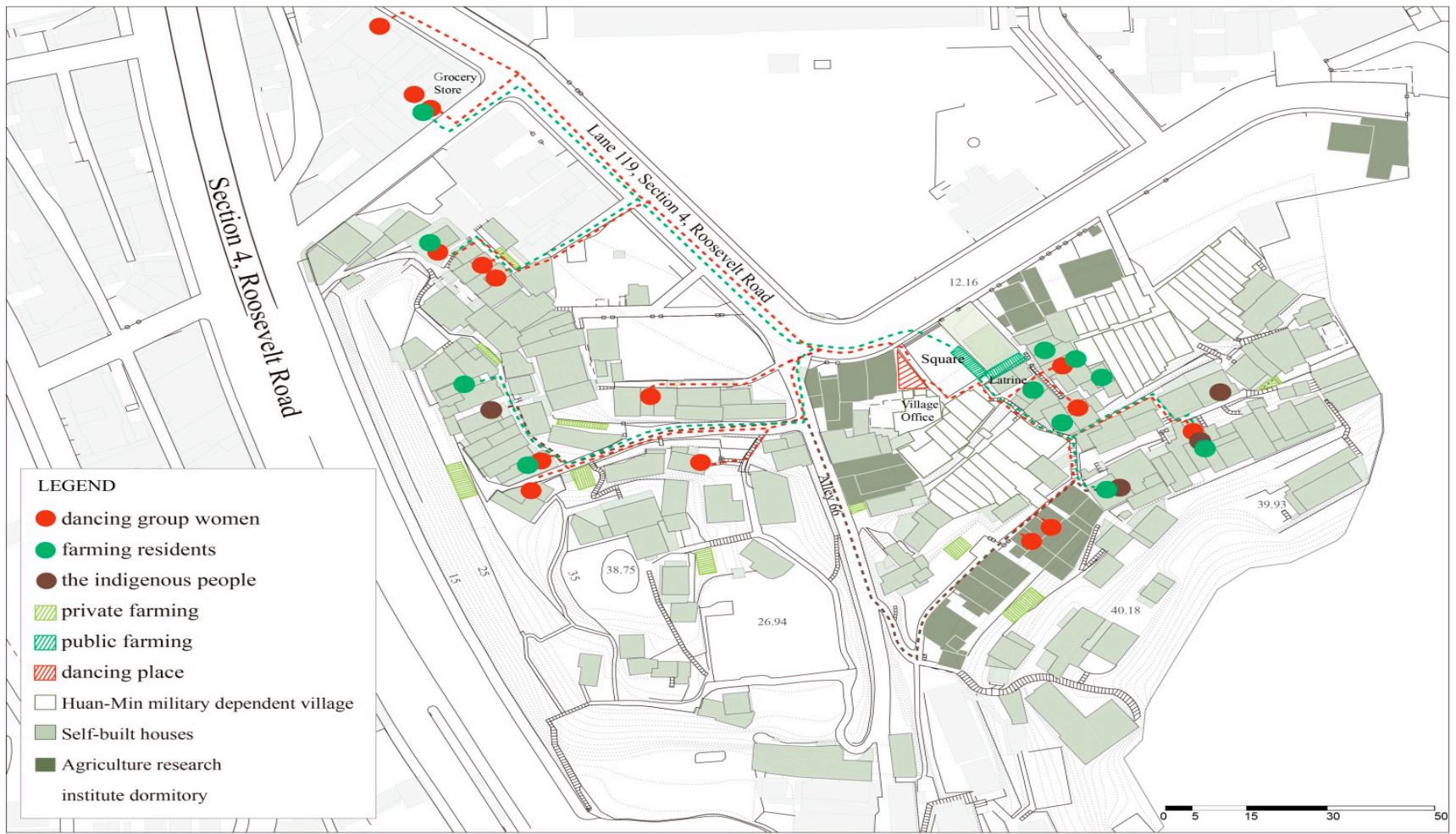

Another layer of boundary debate goes to the different subjectivities affect by the institutional power. The contemporary interventions of the institutional authorities and the conservation movement 
contribute to the boundary transition in the settlement. The social boundaries in the settlement change due to the separated public-owned land authorities. In 2000, the government allotted the east part of the settlement to "National Taiwan University of Science and Technology (NTUST)". NTUST signed a "relocation commitment", promising that all the residents would be properly relocated before new development projects. Paradoxically, after 15 years, it was because NTUST failed to fulfill the relocation commitment, that the settlement is able to maintain the current appearance and the historical fabrics. At the wits' end, NTUST sued two of the households, in order to introduce new campus development plan. On the other hand, in 2009, the west part of the settlement took charge by the "National Property Administration". In other words, the households become the government-managed houses. As a result, the illegal status on law makes the households have to pay a great amount of indemnity and signed the lease with the land management authority. With the different property rights and the lawsuit intervening, the social boundary of residents shifted. It seems that there lies an invisible gap between the east and west part settlement.

It is worth mentioning that there include several subjectivities in the conservation process. The living subjectivity in the settlement is the residents. However, since the east part land is designated as the school site, the students of NTUST somehow own the legitimate subjectivity to use the land. In addition, the conservation group, Good Toad Club represents another subjectivity when facing the political negotiation with the authorities. Nowadays, the conservation group forms a new joint network with the residents and the existing social structure. Also, the NTUST students collaborate with the Good Toad Club to initiated community activities. However, till now, it is the outsiders who have more information and power that represented the local residents to call out their needs in the political negotiation occasion.

Besides the institutional boundary, the conservation movement of the settlement also leads to another positive transformation of the social relations in the community. The talking space of the old veterans in the corner disappear with time, instead, nowadays the new public space, the square, is filled with women exercising group and student initiative activities. Starting from the Good Toad Club activities, for instance, the star theatre, the potluck party, the toad serigraphy, concert, and all kinds of informal small gatherings, the square now becomes a popular activity venue. Currently, the farming project held by the Good Toad Club is still in progress. Through the conservation team, women in the settlement create another public activity that merge the social relations in a new way. Furthermore, some students and the second-generation residents frequently meet in the square at night, forming the so-called "star party". These events bring new life to the settlement.

The place boundary and social boundary are in a dynamic dialectic relation. The separated clusters integrate together as the time goes by. The overlapped spaces also become the common living route. While in recent years, under the legitimacy issue, residents split up again into different parts according to their legal status. And when the conservation group outsiders join in the settlement, there shows another new possible network to fight the eviction as well as building a new community. Moreover, the formation of the conservation group could regard as a public process. It is because these people hold a shared belief, to conserve the overall settlement, that they form the intentional group. These people include tenants in the settlement, students, teachers, and citizens in different professions. The bottom-up conserving process demonstrates an alternative public. Through the conservation movement, especially the involvement of the citizen, a bottom-up planning urged by the grassroots autonomy may lead to a more social-sustainable future of the historical site. 


\section{Conclusion}

The political-economy analysis reveals the structural context behind the formation and the public meaning within the settlement developing process. Since the existence of the informal settlement released the country from the housing crisis, and informally admitted by the state, it represents an alternative public. And, the residents and the informal situation of the settlement, serve as the counterpublics to fight against the domain publics. Re-exam the production of the public and semi-public spaces in the settlement, it is clear that the residents redefine public space by a negotiating way. In contrast to the contemporary designated public spaces from top-down, the bottom-up approach carried out by the residents shows an alternative mechanism of planning in a settlement scale.

The boundary dialectics includes several aspects. In the public-private contention, there are constantly changing boundaries varied from the residents' living space, which not only appeared in the construction process but also in the everyday life. As for the cluster relation, the boundary circle defined by the identity. The clusters merge with others through time and the public activities. While the intervening of institutional authorities tear the overall sense of place into different parts. And the conservation group becomes another subjectivity to face the political negotiation.

Toad Hill is now designated as "cultural landscape" by the Cultural Affairs, with the effort of the conservation group. However, the physical boundary of the cultural landscape and the regulation within this area are still on the debate. When the informal settlement enters into the conservation process, it is unavoidable to face the institutional limitations. How to maintain the organic characteristic of the settlement, the negotiated space produce mechanism, and the housing provision role in the future planning theme, become the challenges to the residents, the conservation group, as well as the government officials. Through the conservation movement, especially the involvement of the citizen, a bottom-up planning urged by the grassroots autonomy may determine the possible future of the settlement.

\section{Acknowledgement}

This paper is derived out of the conservation movement of Toad Hill settlement. It would lose its factual grounding without the participation and the field work of the Good Toad Club members. Finally, I would like to thank my advisor, prof. Kang Min Jay, who encouraged me in writing the paper.

\section{Conflict of Interest}

The authors declare no conflict of interest.

\section{References}

1. C.R. Squires, "Rethinking the black public sphere: An alternative vocabulary for multiple public spheres". Communication Theory, Wiley Online Library. 2002.

2. Fraser, Nancy, "Rethinking the public sphere: A contribution to the critique of actually existing democracy". in Calhoun, Craig (ed.), Habermas and the Public Sphere, Cambridge Mass, MIT Press, 1992. pp. 109-142.

3. Massey, Doreen, "Power-Geometry and a Progressive Sense of Place", in J. Bird \& B. Curtis eds. Mapping the Futures- Local Cultures, Global Changes, London: Routledge, 1993. pp.59-69.

4. Massey, Doreen, "The conceptualization of place”, in Pat Jess\& Doreen Massey eds. A Place in the 
World? Places, Cultures and Globalization, Oxford University Press, 1995.

5. Pile, Steve, "What is a city?", in D. Massey, J. Allen, \& S. Pile eds. City Worlds, Routledge. 1999.

6. Sennett, Richard, "The Civitas of Seeing”. Place: 1988, Vol.5, No.4, pp.82-84.

7. Wills, Jane, "Place and politics," in David Featherstone and Joe Painter (eds.), Spatial Politics: Essays for Doreen Massey, Malden, MA: John Wiley \& Sons. 2013, pp.135-145.

8. 王志弘、沈孟穎、林純秀, 〈族裔公共空間的劃界政治：台北都會區外圍東南亞消費地景 分析〉, 《臺灣東南亞學刊》，2009，6 卷 1期，3-48 頁。

9. 史宓, 《違建社區與財富積累 : 以臺北市寶藏嚴社區為例》, 國立臺灣大學建築與城鄉研 究所碩士論文, 1990。

10. 胡振洲, 《聚落地理學》, 臺北：三民書局，1977。

11. 夏鑄九, 〈（重）構公共空間一理論的反省〉, 《臺灣社會研究》, 1994 , 第 16 期, pp.21-54。

12. 許坤榮, 《臺北邊緣地區住宅市場之社會學分析》。國立臺灣大學土木工程研究所論文, 1987 。

13. 郭肇立, 〈傳統聚落空間研究方法〉, 《聚落與社會》, 臺北：田園城市，1998。

(C) 2015 by the authors; licensee MDPI and IFoU, This article is an open access article distributed under the terms and conditions of the Creative Commons Attribution license. 